\title{
Improved methods of classification of multispectral aerial photographs: evaluation of floodplain forests in the inundation area of the Danube
}

\author{
Tomáš Bucha ${ }^{1} \bowtie$, Martin Slávik ${ }^{2}$ \\ ${ }^{1}$ National Forest Centre, Forest Research Institute, T.G. Masaryka 22, 96092 Zvolen, Slovakia, e-mail: bucha@nlcsk.org \\ ${ }^{2}$ Czech University of Life Sciences, Faculty of Forestry and Wood Sciences, Kamýcká 129, CZ - 16521 Praha 6 - Suchdol, \\ Czech Republic
}

\section{Abstract}

The Gabčíkovo hydroelectric power plant has significantly influenced Danube water regime, thus the condition of floodplain forests in the region. Forest condition has been regularly monitored since 1995 using aerial photos. The subject of this study was to improve the procedure of floodplain forest health evaluation based on digital multispectral aerial images. Firstly, the forest mask was created with overall accuracy $89 \%$, and next, tree health was evaluated using defoliation as health indicator. We applied orthogonal transformation of 4 original bands of multispectral imagery into two-dimensional space. Marginal values of digital numbers (DN) of the first component (New Synthetic Channel - NSC1) were defined by fully foliated willow and poplar. The second component (NSC2) was optimised for damage estimation. Calculated DN values of NSC2 represented a perpendicular distance from the line of DN values of the first component. The distance from the line was proportionate to tree damage extent in a given pixel. We generated linear regression model between pair values of NSC2 and defoliation evaluated for 38 trees in the field, respectively, from aerial photos. A decline prediction resulted in r-square equal 0.86 . Finally, we used the model to predict defoliation for each picture element (pixel) of the component NSC2.

\section{KeY WORDS}

floodplain forest, the Gabčíkovo hydropower plant, defoliation, aerial photos, orthogonal transformation, New Synthetic Channel

\section{INTRODUCTION}

The Waterworks Gabčíkovo was put into operation in 1992. Its construction ensured energy exploitation of the Danube; waterways transport at the critical part of the ford and safety against floods. A crucial Danube part - from Hrušov to Sap - was re-routed into a $31 \mathrm{~km}$ deri- vational canal. Negative impacts on floodplain forests are connected with this solution caused by groundwater level lowering due to drainage effect of the Danube riverbed. Therefore, suitable environment for existence of floodplain forests towards preservation of their productive potential was created by implementing hydrotechnical modifications. Forest health state is monitored 
in transboundary cooperation following the agreement between the governments of the Slovak Republic and Hungary that was concluded in 1995.

Aerial photos are commonly used for ecological monitoring (Morgan et al. 2010). For the purposes of evaluation of forest condition based on infrared photographs, visual interpretation keys were developed (Gross 2000; Ciesla 2000). Damage evaluation is based on a combination of shape, texture, and colour characteristics. Automated procedures of the classification were developed for digital aerial multispectral images. There have been carried out assessments concerning forest damage classification based on the use of the maximum likelihood method (Meddens et al. 2011), regression analysis (Bucha et al. 2009), neural networks (Klobučar 2010), non-parametric k-nearest neighbour method (Eigirdas et al. 2013). In automated approaches, spectral differences between healthy and damaged trees are used for identifying damage extent. High absorption in the blue and red parts of the spectrum and moderately increased reflectivity in the green part of the spectrum are typical for healthy vegetation. Chronic damage causes deterioration of chloroplasts, and this change in tree physiology results in leaves turning yellow, and then the maximum reflectivity moves from the green part to the red part of the spectrum (Zarco-Tejada et al. 2001). High and stable reflectivity in the near infrared range of the spectrum is typical for healthy vegetation. Our measurements of poplar leaves showed high reflectivity for dry and brown foliage as well. Unlike healthy vegetation it was not uniform but was gradually increasing in a range from 700 to $1100 \mathrm{~nm}$, similarly to the pattern observed by Ahern (1988). Slaton et al. (2001) proved relation between infrared reflectance and changes of leaf intra-cellular and cellular structure. Studies on vegetation response to stress showed that within wavelength range from 400 to $850 \mathrm{~nm}$ the maximum difference in reflectance between control and stressed vegetation was close to $700 \mathrm{~nm}$ (Carter and Knapp 2001; Masaitis et al. 2013).

Delineation of tree crowns is necessary for a forest damage classification. Many approaches have been so far proposed to separate tree crowns. Pitkänen (2001), Pouliot at al. (2002), Šumbera (2003), Wang et al. (2006) proposed the automated delineation of tree crowns for black and white, infrared and multispectral aerial images. The authors assumed that the top of the tree can be detected at the highest brightness value. The edge of the crown, on the contrary, represents the minimum brightness value.

Hirschmugl et al. (2007) used stereo images to derive Digital Model of Terrain (DMT). This was used to distinguish individual tree crowns and combined with procedures based on image spectral properties, namely the maximum and minimum reflectance on the top and edge of the crown. Wolf and Heipke (2007) proposed a procedure for automated delineation of tree crowns from infrared images combined with DMTbased fuzzy logic and approximation of tree crown by ellipsis. Bijker et al. (2010) modelled the probability profiles of single tree crowns with Gaussian functions, resulting in delineation of tree crown objects. Jing et al. (2012) proposed a method for individual tree crown delineation based on multi-scale filtering and imagery segmentation. Pontius et al. (2008) used supervised classification - Spectral Angle Mapper method - to identify non-forested areas.

Differences of radiation reflectivity depend on tree species. In the Danube inundation area, there prevail poplars and willows. Higher reflectivity in the visible infrared part of the spectrum is typical for willows and white poplars when compared to that of black poplar. This makes the model for damage estimation harder to derive. The problem was solved by application of multiple regression analysis in previous cycles of forest monitoring in the Danube inundation. Apart from aerial photographs, there were also inserted into the model as a dependent variable, data on a representation of tree species taken from the forest management plan (FMP) (Raši and Bucha 2001) or damage classification was carried out separately for willow and poplar forests (Bucha et al. 2009).

The aim of this study was to improve the procedure of floodplain forests health evaluation based on commercially available aerial photographs. Specifically, our objectives were to:

1. delineate the part of tree crowns on which damage would be evaluated;

2. objectify digital classification of forest condition by transformation of original bands into the component optimised for damage estimation;

3. use the component (derived in the objective 2) in conjunction with ground control data to predict forest health condition over large contiguous areas. 


\section{MATERIAL AND METHOdS}

\section{Study area}

The evaluated area of the Danube left bank inundation is located between the original Danube riverbed and the canal of the Gabčíkovo Waterworks (fig. 1). The area is characteristic of developed river branch system, vast complexes of floodplain forests and alluvial meadows. Forest area is approximately 3000 ha. According to FMP (2005), floodplain forest species composition within the area observed is as follows: $62 \%$ cultivated poplars (Populus sp.), 10\% domestic poplars (Populus nigra L. a $P$. alba L.), 17\% willows (Salix alba, S. fragilis L.), 6\% ash trees (especially Fraxinus angustifolia VAHL.), and 5\% other deciduous trees, especially English oaks (Quercus robur L.), acacias (Robinia pseudoacacia L.), sycamore maples (Acer pseudoplatanus L.) and alders (Alnus sp.).

\section{Aerial photography}

The basic parameters of the aerial photography are described in tab. 1. Organisational and administrative works, as well as all the legal requisites of the aerial imaging, were ensured by the company Photomap Ltd.

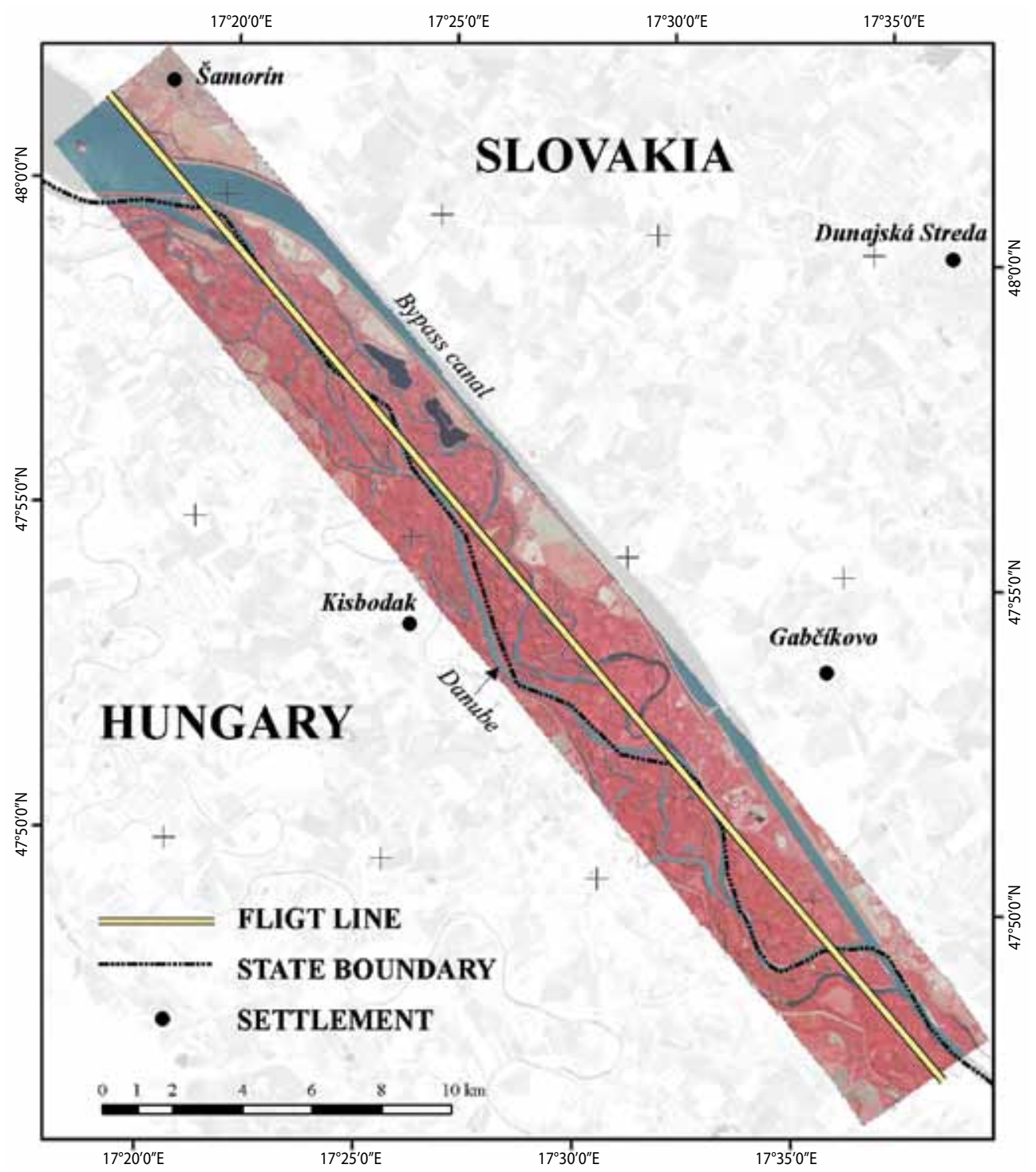

Fig. 1. Study area 
Košice. Photography was performed on $10^{\text {th }}$ September 2011 by the company ARGUS GEO SYSTÉM, Ltd. Hradec Králové using a digital camera Vexcel UltraCamX.

Tab. 1. Selected parameters for aerial photography in 2011

\begin{tabular}{|l|l|}
\hline Locality & Hrušov - Sap \\
\hline Scale & $1: 41800$ \\
\hline Endlap & $60 \%$ \\
\hline Sidelap & No - photography in 1 strip \\
\hline Date of Photography & $10^{\text {th }}$ September 2011 \\
\hline Time of Photography & $11: 00-15: 00$ \\
\hline Type of camera & $\begin{array}{l}\text { UltraCamX - digital multispectral } \\
\text { camera }\end{array}$ \\
\hline Spatial resolution & $30 \times 30 \mathrm{~cm}$ \\
\hline Radiometric resolution & $\begin{array}{l}\text { Blue }- \text { Green }- \text { Red - Near- } \\
\text { infrared band }\end{array}$ \\
\hline Total imaging area & ca. 20000 ha \\
\hline
\end{tabular}

The photographs were supplied in tif format in 8 bit resolution, in the $3^{\text {rd }}$ level of processing, which means that the multispectral channels (blue, green, red and near-infrared) were spatially modified from $90 \times 90 \mathrm{~cm}$ into $30 \times 30 \mathrm{~cm}$ resolution according to the panchromatic band. The area of Hrušov - Sap was depicted in 30 aerial photographs obtained with overlap $60 \%$. All the photographs were ortho-rectified using Image station software. The total root-mean square error (RMSE) did not exceed the value of $\pm 1 \mathrm{~m}$ at individual photographs after their transformation to the national S-JTSK coordinate system. All 30 photographs were used for creation of stereo-pairs for visual assessment of tree defoliation for the purposes of derivation of regressive model for damage estimation. The 13 photographs, specifically the images $4,6,8,10,12,14,16,18,20,22,24$, 26 and 28 (i.e. every second photo from Slovak territory) were used for the classification of forests condition.

\section{Tree defoliation estimation}

Defoliation (loss of assimilation organs) was used as the main indicator and basic visual symptom of tree health. The indicator expresses percentage ratio of missing assimilation organs to the ideal status of the assimilation apparatus, i.e. to a sample fully foliaged tree in given conditions.
The aim of tree defoliation assessment was to obtain support information for the evaluation of the aerial photographs. Defoliation was assessed during field survey and by visual interpretation of the photos on the monitor screen.

During field survey there were chosen 11 areas with healthy to severely damaged trees. The assessment of defoliation was performed on 114 trees by one evaluator at the end of August 2011, i.e. before image acquisition. Defoliation was assessed using binocular - in percents with rounding off to $5 \%$, following the methodology of the international programme UN-ECE ICP Forests (2006). Only 6 from 114 trees were unambiguously identified on the aerial photos. These trees served as a calibration sample for visual interpretation of defoliation from photo stereo-pairs as well as were included into the regression model for damage estimation. Defoliation of further 32 trees was assessed based on stereo-pairs and methodology described in EU's manual (Gross 2000) by the evaluator who carried out a terrestrial assessment. In total, 38 trees were finally used in deriving the regression model for estimation of forest damage based on the aerial photos: 15 willows, 15 poplars and 8 dead trees.

\section{Spectral measurements}

Spectral reflectivity measurements were conducted with Licor-1800 spectroradiometer. External integration sphere LI-1800-12 was used for the measurements in a spectral range $400-1100 \mathrm{~nm}$ with a $2 \mathrm{~nm}$ step. Leaves of black poplar, white poplar, grey poplar, white willow, quaking aspen and dry bark of aspen were analyzed. The leaves were collected in the arboretum Borová hora in Zvolen from the lower part of tree crown in the first decade of August. Measurements were carried out during app. 60 minutes after sample collection. The aim of the measurements was to compare determined spectral reflectivity with $\mathrm{DN}$ values from the aerial photographs and to use the information obtained for verification of the proposed method of forest damage classification.

\section{Creation of the forest mask based on aerial photographs}

Distinguishing forest from other land cover categories, that are overall called forestless, is a significant operation because all the characteristics of forest health are 


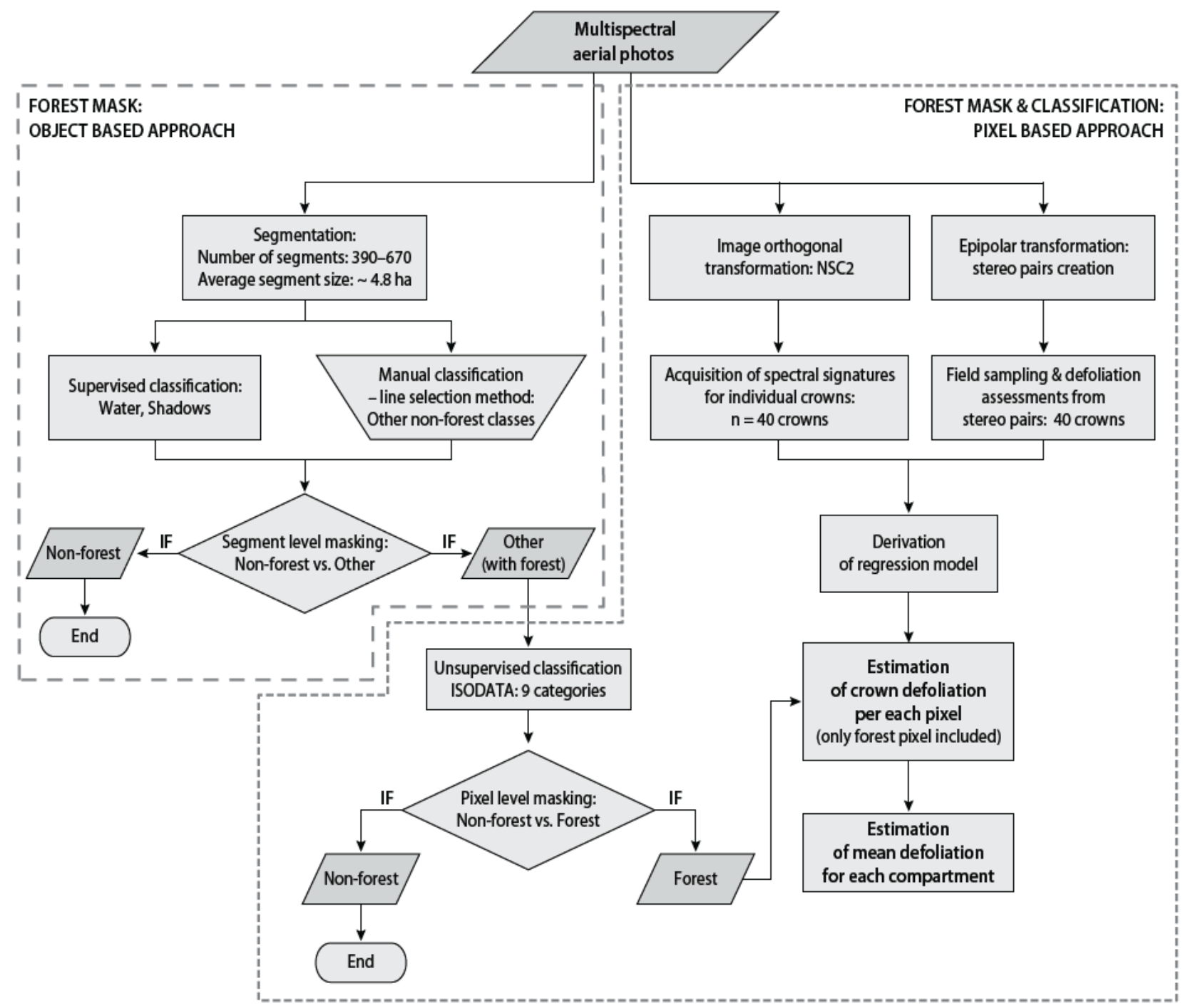

Fig. 2. Working flow of the forest mask creation and tree-crown defoliation estimation

determined based only on pixels classified as forest. We created the forest mask for each photograph. Two basic processes of classification: object-based approach and pixel-based approach were combined (fig. 2).

Image segmentation: object-based classification approach

Object oriented approach was based on image segmentation into more homogeneous objects and performed using eCognition software. After that we carried out combined automated and manual classification of segments into two classes: non-forest (forestless segments) and other (segments with forest).
The aim of image segmentation was to distinguish forest from other land cover classes. Prior to segmentation we reduced the image resolution from $30 \mathrm{~cm}$ to $2.4 \mathrm{~m}$ which made the process of picture segmentation faster (about 30 seconds for $2115 \times 2035$ pixels). Segmentation parameters were set empirically based on quality of visual examination of the results from several image segmentations. We chose the parameters as follows: shape criterion $=0.1$, compactness criterion $=0.5$ and size criterion $=100$.

A low value of the shape criterion means that colour has a great importance at the objects creation. The compactness criterion defined integrity of a resultant object. 
The value 0.5 (middle of the interval $0-1$ ) was selected based on factual occurrence of various object shapes - from compact to non-compact. The size criterion determined the size of the resultant object. The selected value of 100 resulted to number of objects from 390 to 670 in individual photographs. This range allowed effective manual classification of various forestless categories. The "line selection" eCognition functionality which enables selection of several objects with an only draw of a cursor was used. This method of object selection was used particularly for the classification of heterogeneous segments as village with gardens, agriculture areas with hedgerows and individual trees and non-arable areas with shrub succession. Homogenous segments with crops with similar spectral properties as forests as well as water bodies outside forest complexes were also selected by this method and then classified manually into the forestless category.

Automated classification was used for water bodies and shadows occurring spatially inside forest complexes. The size of these segments is usually smaller what makes the manual classification slow. So water bodies as shadows are distinctly spectrally different from forest when their $D N$ value in infrared band is lower then 90. The segment with $D N_{\text {IRED }}<90$ was assigned to the forestless category.

\section{Distinction of tree-crown: pixel-based classification approach}

Subsequently, we distinguished tree crowns from other categories (shadows, small gaps in vegetation, roads and other non-forest objects) inside the segments with forest. Generally, the tree crown is not spectrally homogenous. DN values gradually decrease towards crown edges. This is caused by the fact that the top of tree crown is more illuminated and crown edges are more shadowed. We distinguished tree crowns by applying pixel-based approach. We used the method of Isodata that belongs to the group of unsupervised classifications. Isodata classification was performed independently for each of 13 photographs. We specified 9 output classes and the minimum cluster size: 100 pixels (fig. 5c). Subsequently, we assigned a land cover type to each class. We reclassified the result into the values of 1 - forest and 0 - other categories. The forest mask was obtained with reciprocal combination of outputs from object- and pixel-based approaches to the classification of each of 13 photographs.
First we evaluated the quality of forest masks visually, especially comparing them with photographs. Tree crown were underestimated on the photographs 10 and 12. We enlarged the forest mask (surroundings of classified tree crown) by about 1 pixel in these photos. Forest was overestimated on the photographs 8, 14, 16, 24 and 26 , therefore we reduced the mask by about 1 pixel. Overestimation was caused by inclusion of shadowed parts of crowns into the mask. The technique of picture filtration was used for overestimation elimination with kernel size $3 \times 3$ pixels. No filtering was needed for the photographs 4, 6, 18, 20, 22, 28.

In the next step we created a mosaic from 13 masks. In overlap we took the mask with higher quality according to a visual examination.

\section{Accuracy of the forest mask}

The accuracy of the forest mask was verified on the sample of 100 systematically selected points in a grid $1 \times 1 \mathrm{~km}$ on the mosaic a subset of segments with forest. Correctness of each point assignment into forest or forestless category was visually assessed. The result was processed in a form of error matrix.

\section{REGRESSION MODEL FOR DAMAGE ESTIMATION}

The cornerstone for the derivation of tree damage from the aerial photograph is the intensity of reflected electromagnetic radiation recorded by a digital multispectral camera. A close relation between defoliation evaluated in the field survey and the value of spectral reflectivity recorded with sensors have been proved in several works (e.g. Hildebrandt et al. 1991; Gross et al. 2000; Raši and Bucha, 2001; Bucha et al. 2009). Forest health evaluation was carried out in two stages.

\section{First stage}

In the first stage we derived two components using orthogonal transformation of original $R, G, B$ and $I R$ bands. Mathematic apparatus for the components derivation was the same as described by Jackson (1983). There is a difference in the way of defining the physical meaning of the derived components. In Jackson's approach, the first component represents brightness. It was derived from the points with low and high reflectivity, represented by moist and dry soil. The second compo- 
nent (greenness) represents the amount of green vegetation. In our approach the first component (new synthetic channel - further NSC1) emphasizes spectral variability of individual tree species. The second component (further NSC2) is optimized for damage estimation.

We chose fully foliaged woods (black poplar and willow) with very different reflectivity to compute the $N S C 1$ and we calculated the differences of DN values:

$$
b_{i}=\left(X_{w}-X_{b p}\right)_{i}
$$

where:

$i \quad-1^{\text {st }}$ to $4^{\text {th }}$ channel of the aerial photo $(I R, R, G, B)$,

$X-D N$ value of willow and black poplar.

Low DN values represent black poplars and $\mathrm{Eu}-$ roamerican poplars that have low reflectivity in the spectrum observed ( $B, G, R$ and $I R$ ). The highest $D N$ values are represented by willows and white poplars which usually indicate high reflectivity. $D N$ values (low and high) were calculated as mean values for several poplar and willow crowns distinguished manually on the aerial photos.

We standardized the vector $\boldsymbol{b}=\left(b_{1}, b_{2}, b_{3}, b_{4}\right)$ into the unit vector by dividing each of his elements by the normalization factor $B$ :

$$
A_{1, i}=b_{i} / B
$$

where:

$$
\begin{aligned}
& B=\left(\sum_{i 1}^{4} b_{i}^{2}\right)^{1 / 2} \\
& A_{1, i}-\text { are sought coefficients for the first component } \\
& \quad \text { derivation: }
\end{aligned}
$$

$$
N S C 1=A_{1,1} \times X_{1}+A_{1,2} \times X_{2}+A_{1,3} \times X_{3}+A_{1,4} \times X_{4}
$$

where $X_{i}$ are $D N$ values of pixel in $i$-th channel.

While deriving the $N S C 2$ we defined $D N$ value representing the maximum damage (dead tree) and calculated the difference to any of $D N$ values lying on the line between $X_{w}$ and $X_{b p}$. We chose the value of $X_{w}$ for a calculation:

$$
g_{i}=\left(X_{\text {dead_tree }_{-}}-X_{w}\right)_{i}-D_{2,1} \times A_{1, i}
$$

where $D_{2,1}=\sum_{i 1}^{4}\left(X_{\text {dead tree }}-X_{w}\right) \times A_{1, i}$
Orthogonality of $\boldsymbol{b}$ and $\boldsymbol{g}$ vectors is ensured with described process. Standardization of $\boldsymbol{g}$ vector was carried out by means of normalisation factor $\mathrm{G}$, and transformation coefficients were calculated as follows:

$$
A_{2, i}=g_{i} / G
$$

where $G=\left(\sum_{i=1}^{4} g_{i}^{2}\right)^{1 / 2}$

Calculation of the NSC2 was carried out as follows:

$$
N S C 2=A_{2,1} \times X_{1}+A_{2,2} \times X_{2}+A_{2,3} \times X_{3}+A_{2,4} \times X_{4}
$$

Calculated values of NSC2 component represent a perpendicular distance from the line of $D N$ values of component $N S C 1$ defined by the fully foliated trees of willow and poplar on its borders. The distance from the line is proportional to the extent of the tree damage in the given pixel.

\section{Second stage}

The second stage of forest health evaluation concerned obtaining data on tree defoliation during the field survey or based on visual interpretation on the monitor screen carried out in 3D environment (evaluation of defoliation on stereo-pairs of photographs). For the needs of vegetation health classification we evaluated 38 trees on stereo-pairs of photographs.

Predominant and dominant trees were chosen. Each tree crown was manually vectorised and mean spectral reflectivity was calculated. This spectral characteristic was interconnected with defoliation data, and thus we obtained a set of pair values for further analysis. We derived the regression model by means of simple linear regression analysis between the data obtained both in the first stage (NSC2 component derived from aerial photographs) and in the second stage (defoliation evaluated in the terrain or from stereo photographs). Finally, we estimated the damage for each picture element (pixel) of NSC2 using regression equation (Šmelko 1990).

\section{Results}

\section{Forest mask accuracy}

The forest mask accuracy was verified on the sample of 100 systematically selected picture elements (tab. 2) 
and expressed in a form of error matrix (Congalton et al. 1999).

Tab. 2. Error matrix of the forest mask

\begin{tabular}{|l|c|c|c|c|c|}
\hline $\begin{array}{c}\text { Ground truth: } \\
\text { Classification result }\end{array}$ & Forest & $\begin{array}{c}\text { Non- } \\
\text { forest }\end{array}$ & $\sum$ & $\begin{array}{c}\text { User's } \\
\text { Accu- } \\
\text { racy }\end{array}$ & $\begin{array}{c}\text { Error } \\
\text { of com- } \\
\text { mission }\end{array}$ \\
\hline Forest & 26 & 3 & 29 & $89.7 \%$ & $10.3 \%$ \\
\hline Non-forest & 8 & 63 & 71 & $88.7 \%$ & $11.3 \%$ \\
\hline$\sum$ & 34 & 66 & 100 & & \\
\hline Producer's Accuracy & $76.5 \%$ & $95.5 \%$ & & $89.0 \%$ & \\
\hline Error of omission & $23.5 \%$ & $4.5 \%$ & & & \\
\hline
\end{tabular}

Tab. 2 shows that forest is undervalued. In 8 out of 34 cases, forest was incorrectly incorporated into the category of forestless, which represents $23.5 \%$ underestimation.

On the other hand, there were 3 incorrect cases out of 29 of forest classifications when forestless was incorrectly categorized to forest. This represents $10.3 \%$ overestimation of category forest

The overall accuracy of forest mask creation was $89.0 \%$. We consider this result as acceptable, but not optimal. It points out a need for further refinement of the forest mask delineation algorithm from the photographs with very high resolution.

\section{Transformation of aerial photograph bands for optimization of damage classification}

\section{Measuring leaf spectral reflectivity in laboratory conditions}

In laboratory conditions, with spectral measuring in wave spectrum from 450 to $1100 \mathrm{~nm}$ there was obtained of assimilation apparatus reflectivity of the main tree species in the floodplain forest (fig. 3).

It follows from the results of measurements that wavelengths in the red spectrum (630-690 nm) and in the infrared spectrum (750 to $770 \mathrm{~nm}$ ) are suitable for the distinction of dead trees from healthy ones.

Bark reflectivity from dead poplar was higher in the blue and green part of the spectrum than the reflectivity of willow and poplar leaves' top side and lower (similar) than the reflectivity of the bottom side of willow (poplar) leaves. This fact can noticeably influence utilization of the blue and green channel in damage classification, for example in case of photographs taken in windy conditions. Then, there can be expected higher influence of leaf movements on overall reflectivity and spectral display of leaves and bark (dead trees) may become undistinguishable in the aerial photograph.

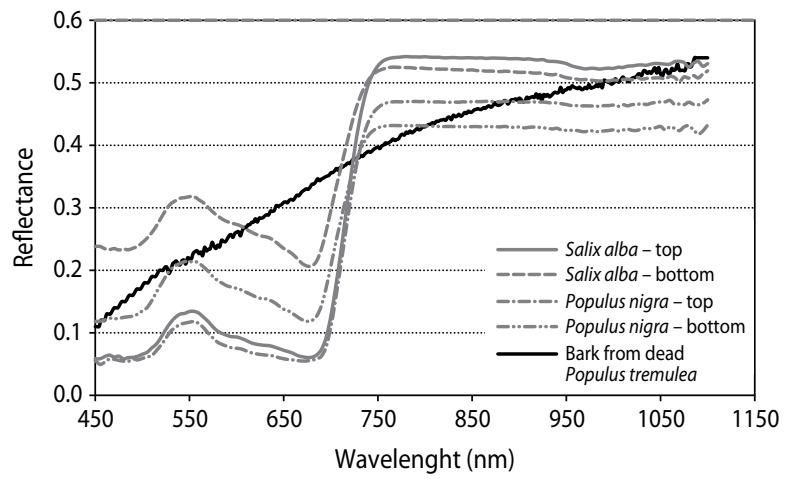

Fig. 3. Spectral reflectivity of the main tree species leaves and tree bark. Top: top of leaf; bottom: bottom of leaf

\section{Derivation of transformation coefficients from DN values of the aerial photograph}

Tab. 3 shows DN values (reflectivity) for willow, poplar, and dead trees, based on which we derived coefficients for computing NSC1 and NSC2 components.

Tab. 3. Input $\mathrm{DN}$ values derived from the aerial photograph

\begin{tabular}{|l|c|c|c|c|}
\hline & $I R$ & Red & Green & Blue \\
\hline & $\begin{array}{c}\text { DN values for poplar, willow and dead tree } \\
\text { according to multispectral bands }\end{array}$ \\
\hline Salix alba & 211.2 & 116.9 & 120.1 & 95.6 \\
\hline Populus nigra & 207.8 & 75.8 & 81.2 & 61.2 \\
\hline Dead trees & 182.2 & 132.4 & 123.9 & 102.5 \\
\hline \multicolumn{5}{|c|}{ Calculation of transformation coefficient of $1^{\text {st }}$ and $2^{\text {nd }}$} \\
component \\
\hline NSC1 & 0.045 & 0.615 & 0.585 & 0.525 \\
\hline NSC2 & -0.968 & 0.209 & -0.136 & -0.011 \\
\hline
\end{tabular}

Similar relationships between DN values of the aerial multispectral bands and reflectivity measured with a Licor apparatus were recorded for white willow, black poplar and dead tree bark. In the visible part of the spectrum $(R, G$ and $B)$ reflectivity of Populus nigra $<$ Salix alba $<$ dead tree. In the $I R$ channel $(755 \mathrm{~nm})$ the relation is as follows: dead tree $<$ Populus nigra $<$ Salix alba. 
Calculation of the components was carried out as a linear combination of original aerial photograph bands (fig. 5b). We used transformation coefficients for the photographs 4 to 24 :

$$
\begin{gathered}
N S C 2_{4-24}=-0.968 \times I R+0.209 \times R+ \\
-0.136 \times G-0.011 \times B
\end{gathered}
$$

For the photographs 26 to 28 we used transformation as follows:

$$
\begin{gathered}
N S C 2_{26-28}=-0.852 \times I R+0.064 \times R+ \\
-0.089 \times G+0.512 \times B
\end{gathered}
$$

where:

$R$ - red channel,

$G$ - green channel,

$B$ - blue channel,

$I R$ - infrared channel.

The reason for application of two equations was the spectral difference between photographs that is probably related to the process of their pre-processing. Different contribution of the blue channel in equations [1] and [2] is mainly visible.

\section{Derivation of regression model for damage estimation}

The results of regression analysis carried out on pair values of the first (NSC2 values) and second stages (defoliation) are regression models (fig. 4), with the help of which we estimated damage for each picture element (fig. $5 \mathrm{~d}$ - right bottom) of the first stage:

$$
\text { Defoliation }_{4-24}=292.7-1.393 \times N S C 2_{4-24}
$$

The correctness of the classification can be assessed based on the parameters of regression analysis (correlation coefficient, standard error of regression line). At relation [3] the correlation coefficient was $r=0.93$ and standard error $s_{y x}= \pm 13.3 \%$, average deviation $d_{i}=10.6 \%$, the range of selection $n=38$ trees. Interpretation of regression line mean error can be illustrated by the following example: if derived defoliation is $30 \%$, in reality it can deviate in a range $\pm 13.3 \%$, i.e. from $16.7 \%$ up to $43.3 \%$ with $68 \%$ reliability.

When continuous decline rating was rounded to the nearest integer for class comparison ( 5 classes - see tab. 4 for class range), the model was able to predict decline with $58 \%$ accuracy.

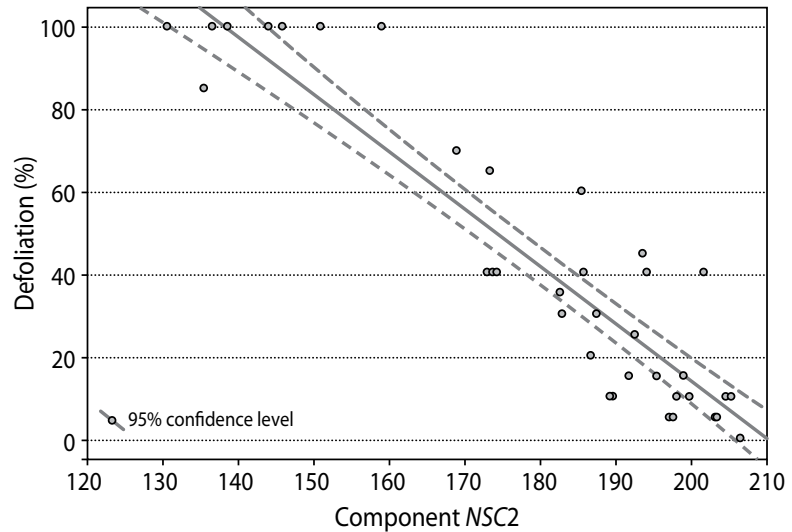

Fig. 4. Graph of a regression model [3] between pair value of first and second stage of defoliation estimation

The parameters (coefficients $a, b$ ) of linear regression in equation [4] for the photographs 26 and 28 was deduced in a simplified way, only from trees with no defoliation and dead trees (i.e. tree with $0 \%$ and $100 \%$ defoliation).

$$
\text { Defoliation }_{26-28}=386.0-2.780 \times N S C 2_{26-28}
$$

Due to simplify way of damage estimation a correlation and mean error of regression line are not derived.

\section{Classification of forest damage}

Information about damage of forests in the area affected by the Gabčíkovo waterworks is presented in tab. 4 and 5. The scale in tab. 4 results from the classification used in the ICP Forests Program (UN/ECE ICP Forests, 2006). Defoliation was assessed for each pixel classified as forest in the process of forest mask creation.

Defoliation calculated for each pixel according to equations [3] and [4] was a basis for computation of damage in forest compartments. Intensity of damage at a level of forest compartment was calculated as arithmetic mean of all forest pixels in the compartment. The summary results are presented in tab. 5 .

In the area investigated, there were only $2.3 \%$ of medium damaged stands - mainly in the north-western part of the study area, where a decrease of groundwater level caused degradation of woody plants. Heavily damaged stands with defoliation above $50 \%$ were not observed at all. 
A

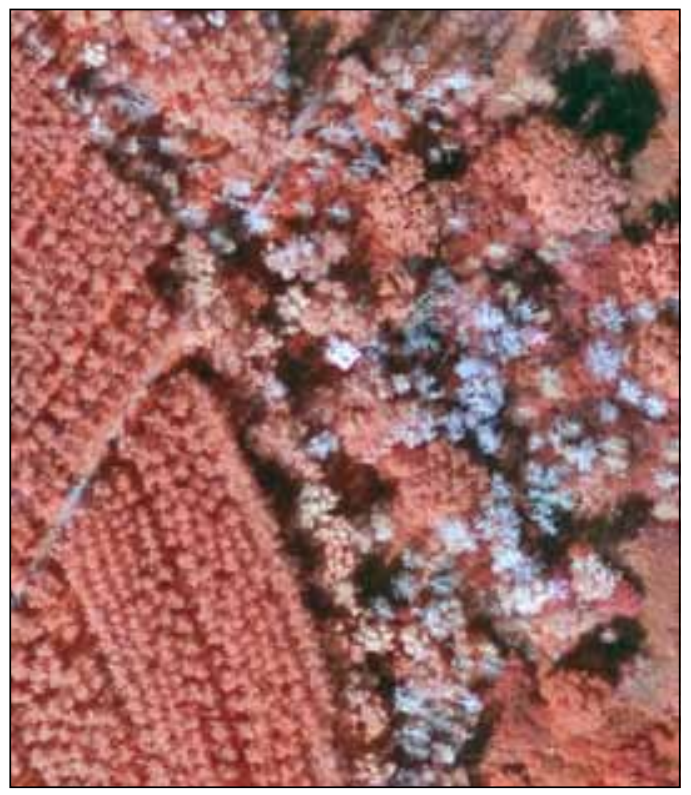

C

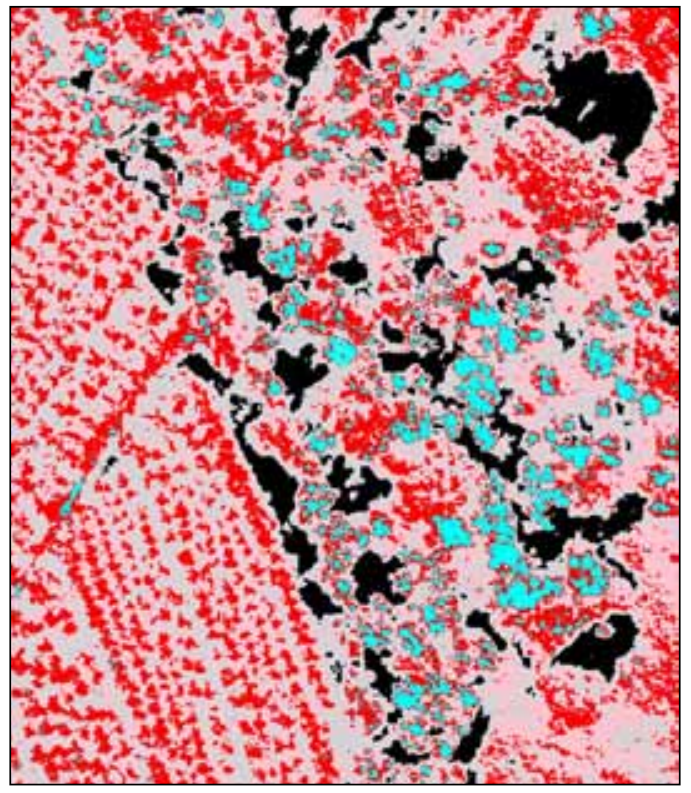

B

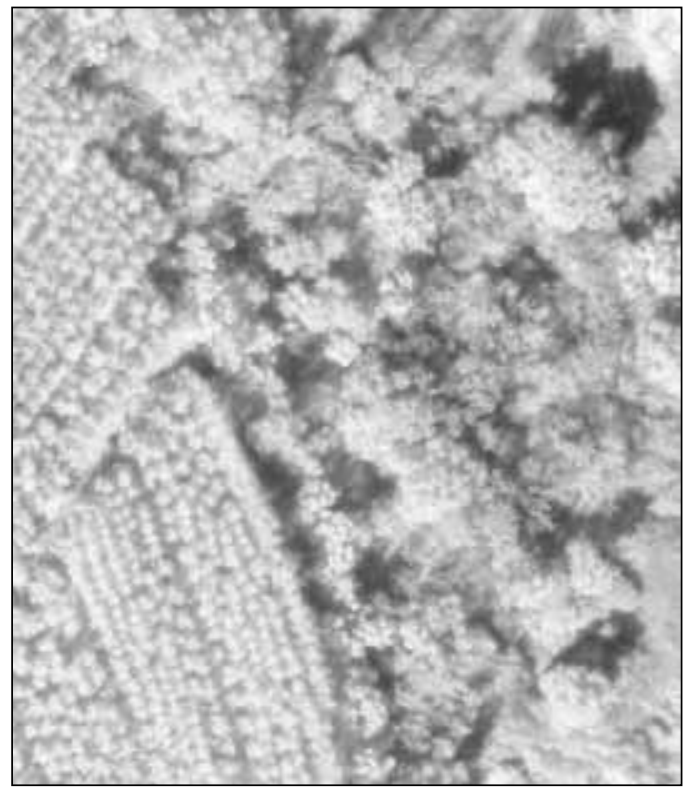

D

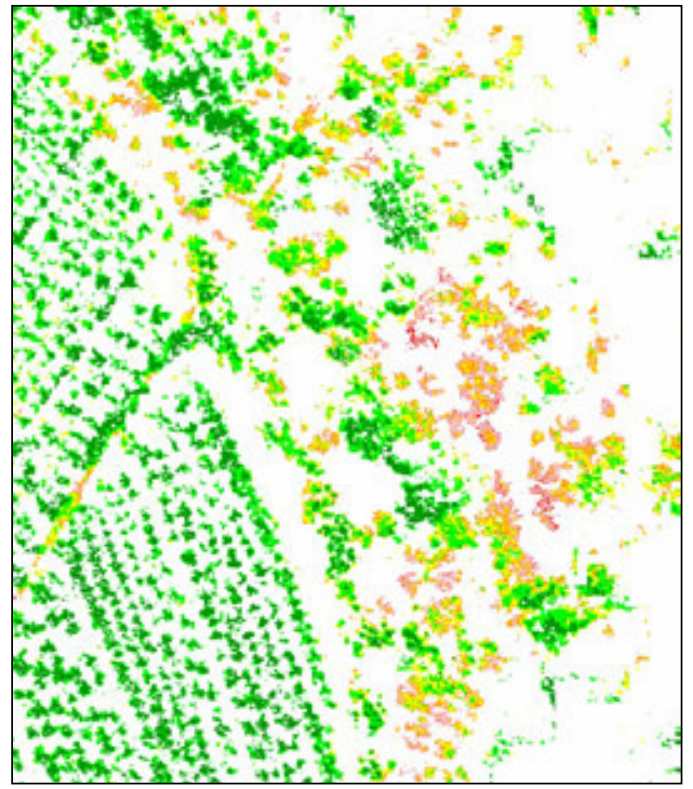

Fig. 5. A: multispectral aerial photograph, combination of bands: IR/R/G. Cultivated healthy poplar trees are shown in red. Redgray colour with variable texture indicates medium to heavily defoliated tree crowns. Deadwood is shown in colours from gray to turquoise. B: NSC2 component derived by orthogonal transformation of original bands of aerial photograph. C: Classification of aerial photographs into 9 categories by Isodata method. D: Classification of tree crown defoliation. Green: healthy vegetation. Red: damaged vegetation 
Tab. 4. Summary of the results on classification at a pixel level in line with UN-ECE ICP Forests methodology (whole observed area)

\begin{tabular}{|c|c|c|l|}
\hline $\begin{array}{c}\text { Defoliation } \\
\text { class }\end{array}$ & $\begin{array}{c}\text { Loss of } \\
\text { assimilation } \\
\text { organs (\%) }\end{array}$ & $\begin{array}{c}\text { \% of the pixels } \\
\text { in defoliation } \\
\text { class }\end{array}$ & $\begin{array}{c}\text { Description } \\
\text { of damage }\end{array}$ \\
\hline 0 & $0-10$ & 38.0 & No defoliation \\
\hline 1 & $11-25$ & 37.3 & $\begin{array}{l}\text { Slight } \\
\text { defoliation }\end{array}$ \\
\hline 2 & $26-60$ & 23.3 & $\begin{array}{l}\text { Moderate } \\
\text { defoliation }\end{array}$ \\
\hline 3 & $61-90$ & 1.3 & $\begin{array}{l}\text { Severe } \\
\text { defoliation }\end{array}$ \\
\hline 4 & $91-100$ & 0.1 & $\begin{array}{l}\text { Dying and } \\
\text { dead }\end{array}$ \\
\hline Total & & 109 & \\
\hline
\end{tabular}

Tab. 5. Summary results of classification at a forest compartment level: frequency of compartments in the defoliation classes in the year 2011

\begin{tabular}{|c|c|c|c|}
\hline $\begin{array}{c}\text { Stand } \\
\text { defoliation } \\
(\%)\end{array}$ & $\begin{array}{l}\text { Description of } \\
\text { damage }\end{array}$ & $\begin{array}{c}\text { Number of } \\
\text { compartments }\end{array}$ & $\begin{array}{c}\text { Frequency } \\
\text { distribution } \\
(\%)\end{array}$ \\
\hline $0-10$ & Healthy stands & 38 & 5.3 \\
\hline $11-20$ & $\begin{array}{l}\text { Healthy stands } \\
\text { with first signs of } \\
\text { damage }\end{array}$ & 482 & 67.1 \\
\hline $21-30$ & $\begin{array}{l}\text { Slightly damaged } \\
\text { stands }\end{array}$ & 181 & 25.2 \\
\hline $31-40$ & \multirow{2}{*}{$\begin{array}{l}\text { Moderately } \\
\text { damaged stands }\end{array}$} & 16 & 2.2 \\
\hline $41-50$ & & 1 & 0.1 \\
\hline \multirow[t]{3}{*}{$51-100$} & $\begin{array}{l}\text { Severely damaged } \\
\text { stands }\end{array}$ & - & - \\
\hline & Together & 718 & 100.0 \\
\hline & $\begin{array}{l}\text { Not evaluated } \\
\text { stands }\end{array}$ & 77 & - \\
\hline
\end{tabular}

\section{Discussion}

A multitask procedure was applied for large area survey of forest condition from multispectral photographs with high resolution $(30 \times 30 \mathrm{~cm})$. Firstly, we focused our research on accurate distinguishing forest from other land cover classes for the reason that all the characteristics of forest health were subsequently derived only from pixels classified as forest. We suggested the method combining object- and pixel-based approaches for the following purposes:

Object-based approach allowed a time efficient classification of large non-forest segments with the use of combined digital and visual classification. One photograph was processed in 100 minutes. The whole area from Dobrohošt' to Sap (13 photographs), including Hungarian Danube area was classified into forest and forestless categories in 22 hours (i.e. 3 working days). Further rationalisation is possible by applying a fully digital algorithm. However, at average size of segment of about 4.8 ha, there can be anticipated a quite complex algorithm due to heterogeneity inside the segments. Therefore, fast visual classification of the segments based on expert knowledge could be considered as a practical and operative solution.

Pixel-based approach was applied as unsupervised classification with Isodata methods for tree crown delineation inside the segments classified as forest. We successfully excluded the most of non-forest vegetation (crops, meadows, bushes, water, shadows) with overestimation error $10.3 \%$ in the category forest. Underestimation error of forest category equal $23.5 \%$ shows a necessity for developing an improved algorithm focused in particular on tree crown delineation.

Secondly our research was focused on to the method for prediction of forest damage. We proposed the procedure based on orthogonal transformation of aerial multispectral bands instead of commonly used spectral indices (Carter 1993, 1994; Sims and Gamon 2002; Vogelmann et al. 1993). The purpose of the transformation was a reduction of four dimensional data into two dimensional space with the aim to optimize information contents. The first component (NSC1) of orthogonal transformation emphasizes spectral variability of individual tree species. The main transformation output is NSC2 component optimized for damage estimation. Consequently, this is a biophysical indicator, the values of which could be recalculated to defoliation through regression with field assessment of defoliation on sample of trees. In the derived regression model concerning damage estimation, the value of correlation coefficient was $r=0.93(r$-square $=0.86)$ and the standard error $s_{y x}$ $= \pm 13.3 \%$. Validation of the continuous decline prediction carried out by Pontius et al. (2008) resulted in $r$ square $=0.71$ and RMSE $=0.582$ for ash forest. Eigirdas et al. (2013) achieved the highest correlation coefficients 
as follows: 0.58 (spruce), 0.60 (pine) and 0.39 (birch) between field-estimated and predicted crown defoliations from Vexcel UltraCam D photographs with $0.5 \times 0.5 \mathrm{~m}$ resolution. They improved the accuracy by aggregating predicted and field estimated tree crown defoliation values up to the sample plot level. Correlation coefficients between plotwise average values of field-estimated and predicted defoliations were around 0.8 .

When continuous decline rating was expressed in 5 defoliation classes, our model was able to predict decline for calibration data with $58 \%$ accuracy and with one-class tolerance with accuracy $95 \%$. In case of 10 classes with $10 \%$ defoliation step, the accuracy would be $39 \%$. Pontius et al. (2008) declared 63\% accuracy using linear regression model with 6 variables ( 6 chlorophyll and canopy water content sensitive indices) for the assessment of ash decline (10 defoliation classes) from hyperspectral imagery.

When compared to the previous monitoring survey (Raši and Bucha 2009) the method proposed is advantageous because of providing possibility to perform forest damage assessment based solely on NSC 2 component derived from aerial data, excluding the need of additional information from the forest management plan.

The method was also verified at an operational level. The study shows that the proposed approach can be used to produce detailed maps of flood forest decline embracing relatively large areas, such as 3000 ha of forest evaluated in the Slovak side of the Danube in this study. Forest monitoring carried out in 3-year cycle of repetition has proved to be sufficiently accurate and - at the same time - economically satisfactory. The total cost of photographs of 20 thousand ha area was $4000 €$, i.e. $0.2 € /$ ha.

Yet, the study showed some problems with processing aerial imagery. Although all the photographs were obtained from one flight line, it was necessary to apply two models for NSC2 derivation. Consequently, there was a need to derive two forest decline prediction models, one for the photographs 4-24 and the second - for the photographs 26-28. The reasons of that could be various, e.g. different quality of images pre-processing or different atmospheric conditions during image acquisition in the upper part of the study area. This suggest the need to examine an use of original multispectral bands in $90 \times 90 \mathrm{~cm}$ resolution for the classification, instead of pre-processed photographs at the level 3 , i.e. spatially modified into 30 $\times 30 \mathrm{~cm}$ resolution according to the panchromatic band.
From forestry point of view, the continuous monitoring in the study area disproved the hypothesis on large-scale and harmful effects of water construction operation on forests situated between Danube original bed and supplying, resp. drainage channel. A version of hydro-technical measures with damming of arm system and water supplying object with volume of water approx. $30 \mathrm{~m}^{3} / \mathrm{s}$, ensures, in most of the area, suitable conditions for healthy development and expected production of wood in floodplain forests.

\section{Conclusions}

The paper describes the improved procedure of surveying floodplain forest condition in the Gabčíkovo region based on the classification of digital multispectral photographs. First, we proposed easily practicable method combining object- and pixel-based approaches for delineation of the part of tree crowns for damage evaluations. Next, the NSC2 component, optimized for the damage estimation, was created by orthogonal transformation of the original bands of multispectral photographs. Then, we used the component in conjunction with ground control data to predict forest health condition over large contiguous areas. The results confirmed that NSC 2 component was a suitable biophysical indicator to provide precise information about forest condition. Furthermore, forest damage assessment was based solely on NSC 2 component without using additional information from the forest management plan.

\section{ACKnOWledgement}

This work was supported by the Cross-border Cooperation Programme Hungary-Slovakia 2007-2013 within the project: Innovative methods of inventory and monitoring of Danube floodplain forests using 3-D Remote Sensing technology (HUSK/1101/1.2.1/0141).

\section{References}

Ahern F. 1988. The effects of bark beetle stress on the foliar spectral reflectance of lodgepole pine. International Journal of Remote Sensing, 63, 61-72. 
Bijker W., Ardila J.P., Tolpekin V.A. 2012. Change detection and uncertainty in fuzzy tree crown objects in an urban environment. In: GEOBIA 2010 proceedings, 29 June-2 July 2010, Ghent, Belgium, IAPRS, ISPPRS, Vol. 38-4/C7.

Bucha t., Barka I., Bartko M. 2009. Zhodnotenie zdravotného stavu lužných lesov v inundacnej oblasti Dunaja v úseku Dobrohošt - Sap z leteckých snímok. Lesnicky časopis - Forestry Journal, 55 (2), 145-164.

Carter G.A. 1993. Responses of leaf spectral reflectance to plant stress. American Journal of Botany, 80, 239-243.

Carter G.A. 1994. Ratios of leaf reflectances in narrow wavebands as indicators of plant stress. International Journal of Remote Sensing, 15, 697-703.

Carter G.A., Knapp A.K. 2001. Leaf optical properties in higher plants: linking spectral characteristics to stress and chlorophyll concentration. American Journal of Botany, 88 (4), 677-684.

Ciesla W.M. 2000. Remote Sensing in Forest Health Protection. USDA Forest Service, FHTET Report No. 00-03.

Congalton R.G., Green K. 1999. Assessing the accuracy of remotely sensed data: Principles and practices. Lewis Publisher, Boca Raton.

Eigirdas M., Augustaitis A., Mozgeris G. 2013. Predicting tree crown defoliation using color-infrared orthophoto maps. iForest, 6, 23-29.

Gross C.P. 2000. Remote sensing application for forest health status assessment. 2nd edition, Commission of the European Communities.

Hildebrandt G. 1991. Remote Sensing Application for Forest Health Status Assessment. Commission of the European Communities, Walphot S.A, 1991.

Hirschmugl M., Ofner M., Raggam J., Schardt M. 2007. Single tree detection in very high resolution remote sensing data. Remote Sensing of Environment, 110 (4), 533-544.

Jackson R.D. 1983. Spectral Indices in n-Space. Remote Sensing of Environment, 13, 409-421.

Jing L., Hu B., Noland T., Li J. 2012. An individual tree crown delineation method based on multi-scale segmentation of imagery. ISPRS Journal of Photogrammetry and Remote Sensing, 70, 88-98.

Klobučar D., Pernar R., Lončarič S., Subašič M., Seletkovič A., Ančič M. 2010. Detecting Forest
Damage in Cir Aerial Photographs Using a Neural Network. Croatian Journal of Forest Engineering, 31, 157-163.

Masaitis G., Mozgeris G., Augustaitis A. 2013. Spectral reflectance properties of healthy and stressed coniferous trees. iForest, 6, 30-36.

Meddens A.J.H., Hicke J.A., Vierling L.A. 2011. Evaluating the potential of multispectral imagery to map multiple stages of tree mortality. Remote Sensing of Environment, 115, 1632-1642.

Morgan J.L., Gergel S.E., Coops N.C. 2010. Aerial photography: A rapidly evolving tool for ecological management. Bioscience, 60, 47-59.

Olofsson K., Hagner O. 2006. Single tree detection in high resolution satellite images and digital aerial images using artificial neural network and geometric-optical model. Proceeding from international workshop 3D Remote Sensing in Forestry, 14-15 February 2006, Vienna, Austria, 205-209.

Pitkänen J. 2001. Individual tree detection in digital aerial images by combining locally adaptive binarization and local maxima methods. Canadian Journal of Forest Research, 31, 832-844.

Pontius J., Martin M., Plourde L., Hallett R. 2008. Ash decline assessment in emerald ash borer-infested regions: A test of tree-level, hyperspectral technologies. Remote Sensing of Environment, 112, 2665-2676.

Pouliot D.A., King D.J., Bell F.W., Pitt D.G. 2002. Automated tree crown detection and delineation in highresolution digital camera imagery of coniferous forest regeneration. Remote Sensing of Environment, 82, 322-334.

Raši R., Bucha T. 2001. The evaluation of forest stands defoliation in the region of water construction system Gabčíkovo using aerial photos. Lesnícky časopis - Forestry Journal, 47 (2), 165-177.

Sims D.A., Gamon J.A. 2002. Relationships between leaf pigment content and spectral reflectance across a wide range of species, leaf structures and developmental stages. Remote Sensing of Environment, 81, 337-354.

Slaton M.R., Hunt R.E. Jr, Smith W.K. 2001. Estimating near-infrared leaf reflectance from leaf structural characteristics. American Journal of Botany, 88 (2), 278-284. 
Strasser T., Lang L., Pernkopf L., Paccagnel K. 2012. Object-based class modeling for assessing habitat quality in riparian forests. Proceedings of the 4th GEOBIA, 7-9 May 2012, Rio de Janeiro, Brasil, $555-560$.

Šmelko Š. 1990. Zistovanie stavu lesa kombináciou odhadu a merania dendrometrických veličín. VPA, VŠLD Zvolen, 1990/6.

Šumbera S., Židek V. 2002. Automated tree top identification using colour infrared aerial photograps of high spatial resolution. Ecology, 21 (3), 229-238.

Vogelmann J.E., Rock B.N., Moss D.M. 1993. Red edge spectral measurements from sugar maple leaves. International Journal of Remote Sensing, 14, 1563-1575.

Wang Y., Soh S.Y., Schultz H. 2006. Individual tree crown segmentation in aerial forestry images by mean shift clustering and graph-based cluster merging. Intrernational Journal of Computer Science and Network Security, 6 (11), 40-45.

Wolf B-M., Heipke Ch. 2007. Automatic extraction and delineation of single trees from remote sensing data. Machine Vision and Applications, 18 (5), 314-330.

Zarco-Tejada P.J., Miller J.R., Noland T.L., Mohammed G.H., Sampson P. 2001. Scalling-up and Model Inversion Methods with Narrow-band Optical Indices for Chlorophyll Content Estimation in Closed Forest Canopies with Hyperspectral Data. IEEE Transactions on Geoscience and Remote Sensing, 39 (7), 1491-1507.

UN/ECE ICP Forests. 2006. Manual on methods and criteria for harmonized sampling, assessment, monitoring and analysis of the effects of air pollution on forests: Part II Visual Assessment of Crown Condition. UNECE, Geneva (www.icp-forests.org). 